\title{
GEOGRAPHIC HOTSPOTS OF CRITICAL NATIONAL
}

\author{
INFRASTRUCTURE
Scott Thacker ${ }^{1}$, Stuart Barr ${ }^{2}$, Raghav Pant ${ }^{1}$, Jim W. Hall ${ }^{1}$, David Alderson ${ }^{2}$
}

1Environmental Change Institute, University of Oxford, South Parks Road, Oxford, UK, OX1 3QY

${ }^{2}$ School of Engineering and Geosciences, University of Newcastle, Newcastle Upon Tyne, UK, NE1 7RU

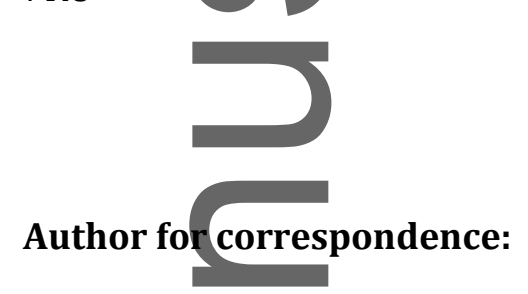

Scott Thacker

Email: scott.thacker@ouce.ox.ac.uk

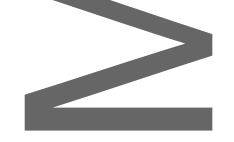

\begin{abstract}
Failure of critical national infrastructures can result in major disruptions to society and the economy. Understanding the criticality of individual assets and the geographic areas in which they are located is essential for targeting investments to reduce risks and enhance system resilience. Within this study we provide new insights into the criticality of real-life critical infrastructure networks by integrating high-resolution data on infrastructure location,

This is auth r manuscript accepted for publication and has undergone full peer review but has not been through in opyediting, typesetting, pagination and proofreading process, which may lead to differences between this version and the Version of Record. Please cite this article as doi: 10.1111/risa.12840.
\end{abstract}

This article is protected by copyright. All rights reserved. 
connectivity, interdependence and usage. We propose a metric of infrastructure criticality in terms of the number of users who may be directly or indirectly disrupted by the failure of physically interdependent infrastructures. Kernel Density Estimation is used to integrate spatially discrete criticality values associated with individual infrastructure assets, producing a continuous surface from which statistically significant infrastructure criticality hotspots are identified.We develop a comprehensive and unique national scale demonstration for England and Wales that utilises previously unavailable data from the energy, transport, water, waste and digital communications sectors. The testing of 200,000 failure scenarios identifies that hotspots are typically located around the periphery of urban areas where there are large facilities upon which many users depend or where several critical infrastructures are concentrated in one location.
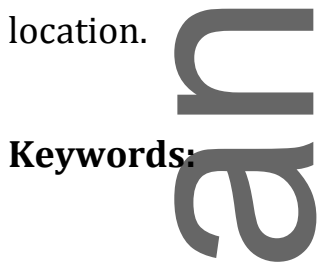

Infrastructure, networks, criticality, interdependence, disruption, Geographic, Kernel density estimation

\section{INTRODUCTION}

Critical National Infrastructures (CNIs) support society and the economy by providing essential services to households and industries. Examples of CNIs include electricity, water, transportation, gas, digital communications and waste networks. Motivated by economies of scale and unequaldistributions of national resources and economic activity, modern CNIs have intolar evolved into large spatially distributed systems with multiple interdependencies.

Such complexity provides the conditions for failure at a particular location to have disproportionate consequences. In the United Kingdom (UK), a number of recent events have highlighted this systemic vulnerability: In 2009, flooding in Cumbria,(1) resulted in a bridge failure that not only caused disruptions to local transportation systems, but also to water,

This article is protected by copyright. All rights reserved. 
electricity and telecoms utilities that were co-located on the bridge. In 2011, power failure at a major exchange in Birmingham resulted in the loss of broadband connection for hundreds of thousands-of users across the UK.(2) On Christmas Eve 2013, the flooding and subsequent failure of three electricity sub-stations at Gatwick airport contributed towards the disruption of 13,000 airline passengers. (3) Motivated by historic failure events and the threats posed to the CNI from a changing climate and human threats, understanding this vulnerability for the purpose of targeting investments to reduce risks and enhance resilience, has become a national priority.(4-8)

In order to effectively target investments we are required to identify 'critical' infrastructure assets "the loss or compromise of which would leave to severe economic or social consequences or to loss of life".(9) Given the 'interconnectedness' of modern infrastructure systems, we are required to think beyond traditional sectorial silos and consider infrastructure as a system-of-systems.(10-12) One major source of interconnection is established through the physical flow of resources between infrastructures, classified as physical interdependencies.(13) A second form of interdependency proposed by Rinaldi et al.(13) is geographic, where the spatial proximity between assets results in their exposure to similar local environmental conditions. Co-location can occur because of physical necessity (i.e. the assets physically depend upon oneanother) or because sites are geographically attractive e.g. on the periphery of urban areas where land is cheaper and may be designated for industrial purposes. In the context of failures, co-location can result in correlated events, which are considered common-cause failure mechanisms.(13) These include: weather related hazard events such as ice storms,(14) flooding,(15) heat waves, ${ }^{(16)}$ or hurricanes, (17); geo-hazards such as earthquakes, ${ }^{(18)}$ volcanic activity, ${ }^{(19)}$ and subsidence, ${ }^{(20)}$; co-location related infrastructure asset failures, ${ }^{(2)}$ and targeted attacks. ${ }^{(21,22)}$ Considering this form of interdependence, we extend our understanding of criticality beyond the scale of an individual asset to identify geographic areas that are in themselves critical.

This article is protected by copyright. All rights reserved. 
Methods and tools from the study of complex networks provide an intuitive means to explore the behaviour of CNIs.(23-25) Within this study, we also make use of this approach; using nodes and edges to explicitly represent the spatial organisation and topological connectivity of CNI systems.(26) A variety of complex network based modelling and simulation tools have been developed to study failure propagation and disruption analysis within physically interdependent CNIs. ${ }^{(27-31)}$ The wide variety of models developed represents not only the different questions that these models seek to inform but also the range of data and computational resource that may be available to the modeller. In a recent review of modelling and simulation approaches for interdependent infrastructure systems undertaken by Ouyang(32), it was recognised that applied studies are limited to two or only a small number of CNIs therefore potentially underestimating the consequences of failure. In order to compare the disruptive impacts of different assets from multiple interdependent CNI sectors, an informative, universal metric for physically interdependent CNIs is required. Casalicchio \& Galli(33) identify that in order to support decision-making for protection and resilience planning, "core metrics" such as those that act at the asset level are required. To this end, Zimmerman \& Restrepo ${ }^{(34)}$ developed a ratio of the temporal disruptions to the supporting and dependent infrastructure, however, despite its universal quality, this metric does not incorporate the magnitude of user disruptions that result from failure events. Johansson and Hassel(28) and Thacker et al.(35) provide a universal metric of infrastructure service losses (user disconnections) applied to individual sectors, however this does not, at the asset level, explicitly incorporate the impacts of indirect disruptions that manifest through nth-order interdependency effects.

Through the removal of infrastructures co-located within previously determined square grid cells, Johansson and Hassel(28) identify critical geographic locations. This work performs an application of the 'cell-space' method that was demonstrated for a university campus, ${ }^{(36)}$ and a road network.(37) Two major limitations of this technique are identified in Wilson(38): (i) that all

This article is protected by copyright. All rights reserved. 
infrastructure locations are considered to be evenly spread across a cell, resulting in a loss of spatial information; (ii) Due to the distribution of point assets in space, the choice of grid cell shapes and locations can have a large impact of outcomes, this is otherwise known as the Modifiable Areal Unit Problem. ${ }^{(39)}$ Kernel Density Estimation (KDE) is a technique that has been developed to produce a single density surface from spatially distributed observations. ${ }^{(40)}$ The KDE creates a continuous surface, any point of which integrates a number of observations (infrastructure assets) within a certain distance that are weighted using a specified kernel function. This reduces the biases associated with the cell-space method by explicitly incorporating the distances between infrastructure assets, preserving detailed spatial information and secondly, providing a continuous (overlapping) kernel function across the entire surface, reducing the impacts of cell boundary choice. Statistical methods such as those proposed by Ord \& Getis ${ }^{(41)}$ provide a means by which to analyse this continuous surface, identifying 'hotspot' locations that are considered as statistically significant outliers.

Wepresent novel methodology and applied analysis that incorporates physical and geographic interdependencies to identify 'infrastructure criticality hotspots' for risk and adaptation planning. In doing so this study makes a number of unique contributions to the literature, these include: (i) Methodology to calculate infrastructure asset user criticality as a universal disruption metric, allowing assets from different sectors to be compared directly with one another. The metric incorporates the potential direct and indirect user disruptions that can result from the failure of the infrastructures through physical interdependencies; (ii) The use of Kernel Density Estimates (KDEs) and statistical testing to calculate geographic hotspots of infrastructure criticality. Hotspots identify concentrations of critical infrastructure that might not otherwise be identified as being critical; (iii) The presentation of a comprehensive and unique national-scale infrastructure criticality assessment for England and Wales that tests

This article is protected by copyright. All rights reserved. 
200,000 failure scenarios by integrating data from the energy, transportation, water, waste and digital communications sectors.

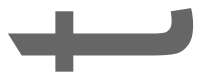

The remainder of this paper is organised as follows: Section 2 outlines methodology to identify geographic hotspots of critical national infrastructure; Section 3 provides a detailed description of an application of the methodology for England and Wales; Section 4 highlights results and findings from the applied analysis. Finally, Section 5 offers conclusions from the study.

\section{DEFINITION OF CRITICAL INFRASTRUCTURE HOTSPOTS (2)}

\subsection{Infrastructure asset criticality}

Consider $Q \subset \mathbb{R}^{2}$ the set of all two-dimensional coordinates of geographical locations within the boundaries of a spatial extent such as a country. The set of users residing within $Q$ who rely upon a variety of essential services that are delivered by the collective function of physical infrastructure assets that make up the national infrastructure are given by $P$. Infrastructure systems intuitively take the form of networks, made up of nodes and edges. Nodes are used to represents point assets such as electricity substations, water pumps and railways stations, whilst edges are used to represent linear assets such as electricity cables, water pipes and railway tracks. Though service delivery also relies on non-physical assets (such as human control), the focus of this study centres on physical infrastructures only.

We collect all assets, $a$, belonging to the national infrastructure to form the set $A=\left\{a_{1}, \ldots, a_{n}\right\}$. Assets belonging to a specific infrastructure type can be collected to form the set $A^{k} \subseteq A$. For example, $A^{e}$ contains all the electricity assets, $A^{g}$ contains all the gas assets and $A^{w}$ is the set of all the water assets. The set of users dependent on a single infrastructure system $A^{k}$ is given as $P^{k} \subseteq P$.

This article is protected by copyright. All rights reserved. 
Infrastructure assets perform different functions in order to satisfy the users dependent on them. To describe this functionality, we characterise three different asset types: sources where services are generated, intermediate - where services are transmitted to other assets, and sink - which distribute services directly to users. This arrangement forms a functional network hierarchy where, at the lowest level, demands for services are placed on sink assets and at the highest level, services are generated at source assets. Intermediate assets support the distribution of services between sources and sinks and in doing so establish directionality of flows within the hierarchy.

We consider each sink asset to serve a unique (non-overlapping) geographic area. As such, the set $A^{k}$ of assets classified as sinks of a given infrastructure type divide the space $Q$ into disjoint partitions. Assuming there are $m$ sink assets in the set $A^{k}$ which divide the space $Q$ into disjoint partitions $\left\{Q_{1}, \ldots, Q_{m}\right\}$, we can estimate the number of users within each partition, we define this as the assets user footprint. Denoting the number of users associated with the sink node of infrastructure $A^{k}$ serving the space $Q_{l}$ as $P_{l}^{k}$, we can construct the sets of all unique subsets of users $\left\{P_{1}^{k}, \ldots, P_{m}^{k}\right\}$ on the infrastructure $A^{k}$. Beyond sink assets, the exact demand placed by the users on the intermediate and source assets depends upon a range of factors that include: which sinks they are connected to, as well as other capacity and functional constraints of the system.

For any give asset (source, intermediate or sink) $a_{j} \in A^{k}$ we can assemble the set $S^{k}$ of all sink assets of the same infrastructure type that it is supplying to. The direct demand placed on $a_{j}$ is denoted by $P_{j}^{d i r}=f\left(\cup_{\forall a_{l} \in S^{k}} P_{l}^{k}\right)$, where the function $f$ depends upon the capacity of the asset to serve the total demand $\bigcup_{\forall a_{l} \in S^{k}} P_{l}^{k}$ of all sinks in the set $S^{k}$. Since assets are also connected across infrastructures (through physical dependencies), there is an indirect demand placed on each asset $a_{j}$ that is supplying resources to another infrastructure type. So for

This article is protected by copyright. All rights reserved. 
example, gas users place an indirect demand on electricity assets due to the existence of a physical dependency between the gas system and the electricity system. We calculate the indirect demand $P_{j}^{\text {indir }}$ in a similar way to estimating $P_{j}^{\text {dir }} . P_{j}^{\text {indir }}=g\left(\bigcup_{S^{v} \neq S^{k}} \bigcup_{\forall a_{l} \in S^{v}} P_{l}^{v}\right)$, where the function $g$ depends upon the capacity of the asset to serve the total demand $\bigcup_{\forall a_{l} \in S^{v}} P_{l}^{v}$ of all sinks in the sets $S^{v}$ belonging to other infrastructures. A variety of models have been developed to estimate direct and indirect demands, represented here by functions $f$ and $g$, for a recent review see.(32) The purpose of this paper is not to develop or promote any specific approach; rather the aim is to integrate outputs from existing models across multiple infrastructure sectors and spatial scales.

For the purpose of targeting investments, we are interested in identifying critical assets, the failure of which can have disproportionate consequences. In developing this analysis, we seek to compare the criticality of all assets within $A$ irrespective of which individual infrastructure system they belong to. To do this, we propose the universal metric: user criticality terine $c_{j}$ that we define as the total number of users who are directly or indirectly dependent on infrastructure asset $a_{j}: c_{j}=\left|P_{j}^{\text {dir }}\right|+\left|P_{j}^{\text {indir }}\right|$. In the context of infrastructure asset failure, this would be the number of users without service.

Figure 1provides a simplified illustrative example to demonstrate infrastructure asset user criticality that can arise through direct and indirect user demands that manifest through physical infrastructure interdependencies. The national infrastructure system $A$ (Part a) of Figure 1) consists of assets from the electricity system $A^{e}=\left\{a_{1}, a_{2}, a_{3}, a_{4}, a_{5}\right\}$ and the gas system $A^{g}=\left\{a_{6}, a_{7}, a_{8}\right\}$. The arrows highlight the direction of service flows through the network hierarchy, from source to sink assets to meet user demands. As well as supporting electridity demands, electricity assets also indirectly enable gas users due to a physical dependency established between the infrastructures. In Part b) of Figure 1 the user criticality calculation for $a_{3}$ is given as the total sum demand imposed due to service flows through the

This article is protected by copyright. All rights reserved. 
network in supporting the direct user footprint established at electricity sink nodes $a_{4}$ and $a_{5}$ and indirect user footprints established at gas nodes $a_{7}$ and $a_{8}$.

\subsection{Geographical location of critical infrastructure hotspots}

The disruptive consequences associated with infrastructure asset failures that are geographically interdependent provide motivation to look beyond the scale of individual assets and identify geographic areas that are in themselves characterised as critical. To address this we propose the concept of an infrastructure criticality hotspot - that we define as a geographic location where there is a concentration of critical infrastructure, measured according to the number of users directly or indirectly dependent on the infrastructure in that location.

Theidentification of statistically significant 'hotspot' areas requires us to calculate the infrastructure user criticality values at all locations within the geographic area being tested. To do this we use KDE, which incorporates discrete assets locations and criticalities to produce a continuous 'surface' for which a criticality density value is available at any location. Using a weighted KDE approach the density $g\left(x_{i}\right)$ at location $x_{i}$ is given by

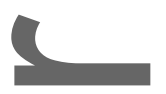

$$
g\left(x_{i}\right)=\left\{\begin{array}{cc}
\sum_{j=1}^{n}\left\{\left[w_{j} c_{j}\right] \frac{1}{\pi h^{2}} K\left(\frac{d_{i j}}{h}\right)\right\}, & \text { if } 0<d_{i j}<h \\
0, & \text { otherwise }
\end{array}\right.
$$

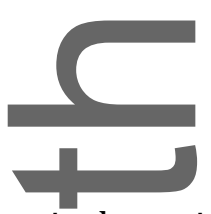

where $w_{j}$ is the weight associated with infrastructure asset $a_{j}, c_{j}$ is the user criticality associated with infrastructure asset $a_{j}, h$ is the bandwidth of the density estimation (the search radius around the location) and $K\left(\frac{d_{i j}}{h}\right)$ is the kernel applied to point $i$. Multiple kernel functions can be selected based on a theoretical, empirical or other functional reason for its use.(38)

This article is protected by copyright. All rights reserved. 
The resulting 'surface' can then be analysed to identify spatial concentrations of critical infrastructures that constitute statistically significant hotspots (high magnitude outliers) of infrastructure criticality. The Getis \& Ord Gi* measure,(41) provides a statistical $z$-score significance test that compares locally calculated values with global values, thus providing a significande test across the whole study area. The $G i^{*}$ value for the location $i$ is given by

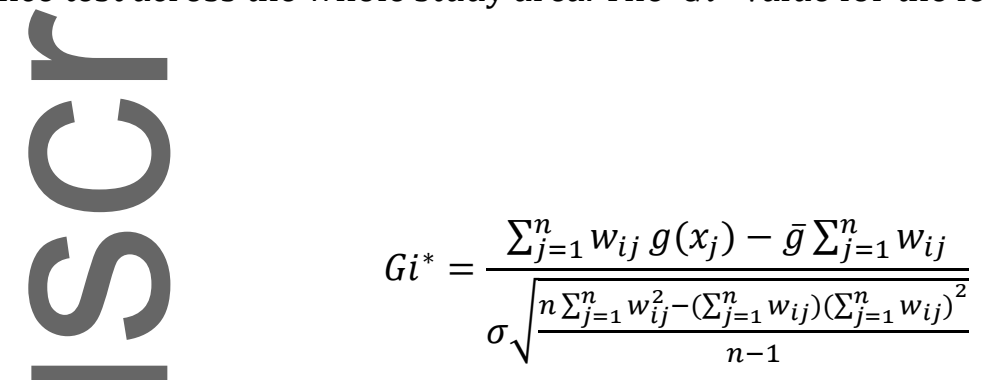

where $w_{i j}$ is the spatial weight between feature $i$ and asset $a_{j}, g\left(x_{j}\right)$ is the KDE value of the attribute of interest at location $j, \bar{g}$ is the global mean of attribute of interest and $\sigma$ is the standard deviation of the attribute. $z$-score significance testing provides a means to identify both hot and cold spots for the analysis.

Figure 2 highlights the key elements of the KDE generation and hotspots derivation process using the same infrastructure system example developed in Figure 1. Figure 2 is split into two parts: Part a) showing how the KDE's key parameters map onto the example area $Q$ for the purpose of generating the continuous criticality density surface; Part b) showing how statistical significance testing of the criticality surface is used to identify geographic hotspots of critical infrastructure.

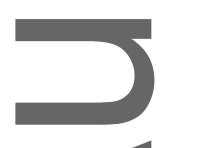

The infrastructure criticality hotspot methodology can be implemented in a number of ways to provide different insights into criticality. These are summarised below:

This article is protected by copyright. All rights reserved. 
- Single sector assets only: Identifies hotspots using only the locations of assets from a single sector.

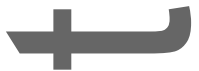

- Multiple sector assets only: Identifies hotspots using the locations of assets from multiple sectors that are all mapped in the same space.

- Single sector with direct users: Identifies hotspots using locations and direct user weightings for only a single sector.

- Multiple sector with direct users: Identifies hotspots using locations and direct user weightings from multiple sectors that are all mapped in the same space.

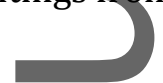

- Single sector with direct and indirect users: Identifies hotspots using locations and user criticality weightings (direct and indirect demand) for only a single sector.

- Multiple sector with direct and indirect users: Identifies hotspots using locations and user criticality weightings (direct and indirect demand) from multiple sectors that are all mapped in the same space.
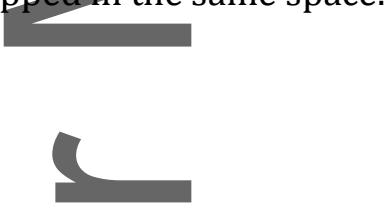

The choice for implementation of the analysis will depend upon the questions that drive the analysis and practical constraints, such as lack of available data or computational constraints. The incorporation of increasing levels of data into the analysis (such as the analysis of multiple sectors and user criticality values) promotes the identification of geographic locations that might not otherwise have been identified.

In the following sections, we provide a demonstration of this methodology for England and Wales using data from multiple sectors. We use direct and indirect demands to estimate asset user criticalities and produce hotspot maps for individual and multiple sectors to draw out important insights into national infrastructure criticality and vulnerability.

This article is protected by copyright. All rights reserved. 


\section{APPLICATION TO CRITICAL NATIONAL INFRASTRUCTURE IN}

\section{ENGLAND AND WALES}

\subsection{Overview of the analysis}

We provide a comprehensive national scale demonstration of the methodology for England andyales utilising unique data from the energy, transport, water, waste and digital communications sectors. For each sector, direct user estimates are used to derive asset user criticality values. The integrated electricity network is central to the national infrastructure provision, with allother sectors physically dependent on electricity for their operation. Given its importance, we characterise the user criticality of electricity assets based on direct and indirect users that are established due to this dependency. Geographic interdependency is characterised through the derivation of infrastructure criticality hotspots using KDEs.

The following sub-sections provide a detailed account of the methods and data used in the analysis, this includes: (a) Infrastructure asset representation: the integration of highly detailed data on infrastructure location, interconnectivity and interdependence to build a national infrastructure representation; (b) Infrastructure criticality calculation: applied methodology and data for calculating asset criticalities using user estimates derived from usage statistics, spatial density estimates and network-based path assignment techniques and (c) Infrastructure criticality hotspot identification: details for implementation of the KDE and statistical significance testing for the purpose of hotspot identification.

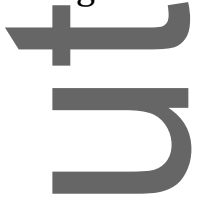

\subsection{Infrastructure asset representation}

In order to calculate asset criticality values, we first map all infrastructure assets from the national infrastructure $A$ within the area of the study $Q$ (England and Wales). Table I

This article is protected by copyright. All rights reserved. 
presents the real infrastructure asset data from multiple sectors that have been used in the analysis, including reference to where the datasets originate. This includes a representation of the integrated electricity network, where nodes are used to represent generation facilities and electricity substations and edges are used to represent overhead lines and underground cables. Figure 3(a) provides a representation of this network, showing the different voltage levels at which connections to generators and other infrastructures are made. Other network infrastructures include the national road network, where nodes represent junctions and edges represent different road segments. Similarly, the national railway network in comprised of nodes that represent junctions and stations and edges represent track segments.

The location of airports, ports, water towers, wastewater treatment plants and telecommunication towers are represented as single point assets, identified by nodes. Each asset of these specific types is dependent on electricity for its operation. In many cases, the nature of the physical connection between the dependent asset and its supporting electricity asset is unknown. We build a dependency edge between the asset and its nearest (geographically closest) electricity asset of appropriate voltage, this assumes a least cost (in terms of length of buried cable or installed overhead line) decision for connecting infrastructures and is seen in practice in airport(42) systems and railway(43) systems. Figure 3 (b) provides an example of this, showing the physical connections that are established between gas take-off points and the $33 \mathrm{kV}$ electricity substation assets.

\subsection{Infrastructure criticality calculation

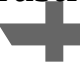

Having mapped the assets within England and Wales, we next calculate their criticality $c_{j}$. The first step of this process is to calculate the numbers of users directly dependent on all assets $\left|P_{j}^{d i r}\right|$. Table I provides details for how users are allocated to infrastructure assets from different sectors. In summary: Point assets representing airports are derived from annual flight 
statistics and are calculated as the total number of terminal passengers for an average day in 2009.(44) Similarly, average daily port users were derived using 2009 national port usage statistics.(45)

In the absence of user data for the gas take-off points, electricity distribution substations, water towers, wastewater treatment plants and telecommunication towers assets, we estimate these using a Voronoi decomposition technique.(29,35) Assignment of users is a two part process comprising: (i) deriving infrastructure asset footprints to estimate spatial area of influence around each distribution level asset, and (ii) assigning user counts to each distribution level assetbased on a spatial union of asset footprint with census derived population estimates (that we take as an estimate for domestic demand). This method assumes each asset provides an equally weighted service and assets influence only the closest space around them. Insights derived from this study should take into consideration uncertainties in estimations of user demands that arise due to the aforementioned assumptions. Figure 4 (a)-(h) highlights the process of user assignments and provides results (with user counts highlighted on a colour scale) derived for wastewater treatment works, gas off-take points, telecommunication masts and water towers respectively.

Direct (electricity) and indirect (non-electricity) user demands that are concentrated at sink nodes are then allocated to intermediate and source nodes within the integrated electricity network. Due to the lack of availability of user demand data for these assets, allocations are made on the assumption that electricity flows are established along a set of shortest paths between generation (source) and consumption (sink) nodes through the network. To achieve this we perform an application of the capacity constrained location-allocation method as outlined in Thacker et al.(35). In summary: The method calculates the set of shortest paths between source and sink nodes in the network that are required to satisfy user demands - the selected path set is constrained by the capacity of generators only. Users are aggregated at

This article is protected by copyright. All rights reserved. 
assets within paths between sink and sources and these aggregations correspond to asset criticality values.

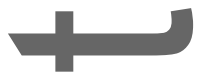

User demands for the major road network were derived from Department for Transport Average Annual Daily Flows (AADF) usage statistics, ${ }^{(46)}$ which give aggregated estimates of number of vehicles of different types (two-wheelers, cars, taxies, buses, coaches, light goods vehicles andheavy goods vehicles) along major roads in Great Britain. We have converted these to passenger counts by multiplying the vehicle numbers by passenger occupancy factors provided by transport analysis guidelines handbooks.(47) Figure 5 (a) shows the major road network with edges weighted based on traffic flows.

Usage of the railway network was derived from a rail trip distribution model developed in previous work by Pant et al.(43). The model uses information from train timetables and station usage statistics to estimate trips being made between station pairs. The results are aggregated as origin-destination (O-D) daily trip assignments of passengers in the railway network. Figure 5 (b) represents the flows of all passengers through stations and along routes for the national railway network of Great Britain.

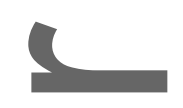

\subsection{Hotspot identification}

A $1 \mathrm{~km}$ sampled spatial lattice was constructed across all of England and Wales. A $1 \mathrm{~km}$ lattice was-chosen as it provided a suitable compromise between providing a high-density spatial coverage of England of Wales so that locations of relatively low electricity infrastructure assets were still represented in analysis whilst making the analysis computationally tractable. Additionally, and considering the suggested level of result interpretation, the $1 \mathrm{~km}$ lattice size provides sufficient granularity to mitigate the impacts of choice regarding exact geographic placement of lattice. The individual points in the lattice formed the sample locations at which

This article is protected by copyright. All rights reserved. 
KDE estimation was performed to obtain an estimate of the spatial density of infrastructure occurrence and related user density per infrastructure sector. The output units of the KDE analysis were density per-km².

For each location in the lattice a spatial density estimate was derived using a weighted

intensity KDE approach as presented in EQ. 1. A Gaussian kernel of the form $K\left(\frac{d_{i j}}{h}\right)=$ $\left\{\frac{1}{\sqrt{2 \pi}} \exp \left(-\frac{d_{i j}^{2}}{2 h^{2}}\right)\right\}$ was selected to incorporate the decay in spatial influence that is associated with a sampled/ocation. A Gaussian kernel was chosen in preference to other forms (e.g., uniform, triangle, quartic) as a smooth continuous density output,(40) was required that minimised sharp changes of estimated asset density across England and Wales. For each infrastructure sector considered in Table $1 \mathrm{KDE}$ surfaces were derived both in terms of the spatial frequency of infrastructure assets (i.e., without any measure of associated user criticality such that $c_{j}$ was set to $1 \forall j \leq h$ ) and also in terms of user criticality, with $c_{j}$ set to the user counts associated with a particular infrastructure asset $j$. A weighting of $W_{a}=1$ for all infrastructure types, establishing no preference for a particular infrastructure systems type. All KDE surfaces were derived for a bandwidth $(h)$ set to $5 \mathrm{~km}$ by experimentation and chosen as the best compromise between the bandwidths generated automatically for the different infrastructure assets under investigation using the optimal bandwidth for a Gaussian distribution presented by Silverman(40).

Torecognize statistically significant spatial hotspots of infrastructure criticality the Getis and Ord $G i^{*}$ spatial hotspot statistical test was employed. Formally, the Getis and Ord $G i^{*}$ value for a location $i$ is calculated using EQ.2. where in the case of this study, each $1 \mathrm{~km}$ sampled lattice location in an infrastructure sector formed the locations $i$. To test for statistical significant hotspot locations, the Z-score of each location $i$ was threshold at a 99\% significance level $\left(G i^{*}>2.6\right)$.

This article is protected by copyright. All rights reserved. 


\section{RESULTS}

\subsection{Overview of the results}

The following subsections provide the results for the applied study in England and Wales. The hotspot results are presented in different sub-sections that relate to different combinations of infrastructure asset types, these are: (i) Non-transport asset types - including electricity, gas, telecoms, water and water treatment assets, (ii) Transport asset types including rail and road assets and (iii) Composite analysis - which includes all of the nontransport and transport assets from the study. Presentation of the hotspot results by asset type enables insights to be gained in relation to the individual infrastructure systems underlying form and functionality.

Within the analysis, a focus has been placed on highlighting the different hotspots that are generated using different levels of data. This includes data that simply encodes the asset location; data that encodes the asset location with direct user demands and finally; data that encodes asset location and indirect user demands. This analysis has been developed to highlight how, through the incorporation of data on customer usage and physical interdependence, hotspots that might not otherwise be identified in more simple analyses can be derived. This is further exemplified through the mapping of user criticality hotspots to city boundaries (population dense area), that are typically the focal point for risk reduction and resilience building interventions.

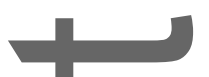

\subsection{Non-transport asset criticality}

Error! Reference source not found. (a) shows the estimated spatial density of nontransportinfrastructure assets for England and Wales (electricity transmission Grid Supply Points (GSP), gas transmission take-off points, water towers, waste water treatment works and telecom towers/masts). Large density values occur in south-west Wales, south-east Midlands

This article is protected by copyright. All rights reserved. 
and also in the west of England. However, when measured in terms of criticality, the spatial density and subsequent hotspots are focused on the major urban conurbations of England and Wales Error! Reference source not found. (b); namely, London with a tapering to the surrounding south-east region, Liverpool and Greater Manchester, Birmingham and Leeds areas.

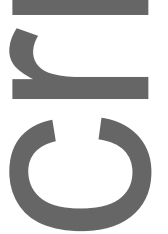

The criticality metric based on direct users of electricity network assets is shown in Figure 7 (a).Notsurprisingly the major urban conurbation of England and Wales form the major demand hubs for electricity infrastructure network assets. The full demands on electricity assets - user criticality (direct and indirect users) due to the dependence of the GSP, gas, telecoms, water and water treatment assets on the electricity network is shown in Figure 7 (b). When physical interdependence is taken into account, the map of critical asset density is more spatially dispersed than when just considering the direct usage of electricity infrastructure. The overall electricity results suggest that a relatively small number of key geographical locations play a major role in satisfying electricity demand within England and Wales, particularly with respect to the dependence of other non-transport infrastructures on the electricity network.

The largest magnitude hotspot of electricity demand in the south-east is located to the east of the Greater London Authority (GLA), showing the key role that large regional grid supply points play in satisfying the electricity demand of London and the south-east Figure 8 (a). This relationship of large non-urban regional electricity infrastructure assets satisfying urban users is more evident outside of London. For example, Figure 8 (b) shows the hotspots in South Yorkshire between Leeds and Sheffield. Similar non-urban demand hotspots are found running north to south through the east Midlands and also to some extent in the Liverpool to Manchester corridor in the north-west.

This article is protected by copyright. All rights reserved. 


\subsection{Transportation asset criticality}

The KDEs and associated hotspots for the rail and road transport infrastructure have been computed using direct user demands mapped to each transport type (i.e. rail passengers assigned to rail assets and road passengers assigned to road assets). KDE results Figure 9 (a) show that there are only a small number of noticeable hotspots of criticality outside London for the railway infrastructure. In the case of London, disruption radially propagates along the mainline railconnections into the south-east. The result is a large hotspot for London and the mainline rail corridors connecting it, with only four other much smaller (both spatially and in terms of magnitude) hotspots occurring at Liverpool, Greater Manchester, Birmingham and Leeds.

A slightly more complex relationship exists between road assets and related criticality compared to rail. Larger more significant densities of criticality are found outside London Figure 9 (b). Resulting hotspots of criticality are focused around principal motorways, in particular the M25, M1, M6 and the local motorways of Greater Manchester and Leeds, including the M62.

\subsection{Composite asset criticality}

Composite criticality analysis involves the mapping of the non-transport infrastructure assets and transport assets in the same geographic space. KDEs have then been computed at individual locations $x_{i}$ by summing the user criticalities of non-transport and transport assets at that location. The composite criticality hotspots analysis Figure 10 (a) and Figure 10 (b) shows the major role that the large urban areas of England and Wales have both in terms of the demand for infrastructure services and also in terms of spatially accommodating these. The composite analysis (combination of criticality for individual assets, interdependence with the

This article is protected by copyright. All rights reserved. 
electricity network and transport disruption) shows that London is a major focus of criticality; it has a spatially continuous hotspot with multiple peaks that covers a spatial extent of approximately 2,331 sq-km 63 km west-to-east and 37 km north-to-south; Other composite hotspot locations are found in or around Greater Manchester, Liverpool, Leeds and Birmingham. However, the magnitude of these is lower than the London and the spatial extent significantly smaller (e.g., the largest hotspots are 256 sq-km Manchester, 115 sq-km Liverpool, 110 sq-km Leeds and $153 \mathrm{sq}-\mathrm{km}$ Birmingham. A cluster of smaller hotspots (between approximately 8 and 26 sq-km) are found in the Sheffield, Derbyshire and Nottinghamshire, and Humberside areas which are a result of the strong hotspots previously noted in these regions relating to electricity assets meeting user demand.

\section{CONCLUSIONS}

In this study, we have developed methodology that incorporates both physical and geographic infrastructure interdependencies to identify infrastructure criticality hotspots. The methodology has been applied at the national scale for a range of infrastructure types in England and Wales.

Through application of the methodology to a real-world system we were able to highlight areas of infrastructure criticality in England and Wales that can be targeted for investment to reduce risks and enhance resilience. The differences observed in hotspot maps created in the result section highlight the importance of evaluating criticality as a function of direct and indirect infrastructure users, rather than infrastructure asset concentrations. Although many hotspot locations rather intuitively correspond to areas of high user density, other, non-intuitive locations are also highlighted. These typically exist on the peripheries of cities where dependence is focused onto a small selection of infrastructures located outside of urban areas. By mapping user criticality hotspots with city boundaries, we show that the

This article is protected by copyright. All rights reserved. 
analysis described herein provides new insights when compared to observing city boundaries themselves or population density mappings (cities having high population densities).

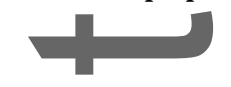

The general methodology developed in this paper is not only applicable to different
geographic areas, but also to a broad range of infrastructure types, providing a means to explore the relationships that exist between different infrastructures at a variety of operational and spatial scales. There are many natural extensions to this work that include, (i) the development of methodology and applied analyses to incorporate logical and information interdependencies, (13) into a single framework with physical and geographic interdependencies; (ii) the development of risk assessment that integrates a mapping of infrastructure criticality with a spatial representation of hazard likelihood and quantification of the consequences of failure in economic or other terms; (iii) The incorporation of hotspots into a decision making framework designed to inform prioritization of investment in system resilience. A dynamic approach for estimating hotspots that incorporated the time varying characteristics of supply and demand would be a valuable extension to this work, though the data and computation requirements to facilitate such an analysis may prove prohibitive.

Assembling the data for such an analysis represents a significant challenge. This is not only because of the variety of data needed from different sectors, but also because information on infrastructure users are often restricted due to matters relating to privacy, security or commercial sensitivity. Due to these complexities, where data have not been available, we have adopted an approach that allocates users to assets through Voronoi decomposition and network path based assignments. Despite the KDE approach reducing certain biases introduced in cellspace methods, the approach does however require a number of parameters to be estimated (grid size and location, bandwidth etc.) - such estimations introduce biases in their own right and these should be recognised when communicating results.

This article is protected by copyright. All rights reserved. 
In conclusion, the methodology and analysis presented herein provides a range of decision makers with the ability to identify infrastructure criticality hotspots. Such an analysis provides useful evidence and insights for assessing the vulnerability of modern interconnected infrastructure systems.

\section{ACKNOWLEDGMENTS}

The research reported in this paper was part of the UK Infrastructure Transitions Research Consortium(ITRC) funded by the Engineering and Physical Sciences Research Council under Programme Grant EP/I01344X/1. Additional support to Scott Thacker was provided by ARUP. The authors are grateful to David Penhallurick and Richard Ploszek from Infrastructure UK (in HM Treasury) who provided motivation for, and advice during, this study.

\section{REFERENCES}

1. Miller JD, Kjeldsen TR, Hannaford J, Morris DG. A Hydrological Assessment of the November 2009 Floods in Cumbria, UK, 2013.

2. BBC. BT Suffers Huge Broadband Failure. Available at: www.bbc.co.uk/news/technology15154020 , Accessed October $3^{\text {rd }}, 2011$.

3. McMillan D. Disruptions at Gatwick Airport - Christmas Eve 2013. Report by David McMillan to the Board of Gatwick Airport Limited, 2014.

4. CST.A National Infrastructure for the 21st Century. Council for Science and Technology, 2009.

5. POST. Resilience of UK Infrastructure. Parliamentary Office of Science and Technology POSTNOTE: Number 362, October, 2010.

This article is protected by copyright. All rights reserved. 
6. DEFRA. Climate Resilient Infrastructure: Preparing for a Changing Climate. Department for Environment, Food and Rural Affairs, 2011.

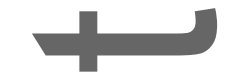

7. Cabinet Office. Keeping the Country Running: Natural Hazards and Infrastructure, 2011.

8. ASC.managing Climate Risks to Well-Being and the Economy. ASC progress report. Adaptation Sub-Committee, 2014.

9. Cabinet Office Strategic Framework and Policy Statement on Improving the Resilience of Critical Infrastructure to Disruption from Natural Hazards, 2010.

10. Kröger W.Critical infrastructures at risk: a need for a new conceptual approach and extended analytical tools. Reliability Engineering and System Safety, 2008; 93(12), 17811787.

11. Eusgeld I, Nan C, Dietz S. System-of-systems approach for interdependent critical infrastructures. Reliability Engineering and System Safety, 2011; 96(6), 679-686.

12. Tran M, Hall JW, Hickford AJ, Nicholls RJ, Alderson D, Barr S, et al. National Infrastructure Assessment: Analysis of Options for Infrastructure Provision in Great Britain, Interim Results: Environmental Change Institute, University of Oxford, UK, 2014.

13. Rinaldi SM, Peerenboom JP, Kelly TK. Identifying, understanding, and analyzing critical infrastructure interdependencies. Control Systems, IEEE, 2001; 21 (6), 11-25.

14. Chang SE, McDaniels TL, Mikawoz J, Peterson K. Infrastructure failure interdependencies in extreme events: power outage consequences in the 1998 ice storm. Nat Hazards, 2007; 41:337-358.

15. Pitt, M. Learning Lessons from the 2007 Floods. Pitt Review, 2008.

This article is protected by copyright. All rights reserved. 
16. McColl L, Palin EJ, Thornton HE, Sexton DM, Betts R, Mylne K. Assessing the potential impact of climate change on the UK's electricity network. Climatic change, 2012; 115 (3-4), 821835.

17. Loggins RA, Wallace WA. Rapid assessment of hurricane damage and disruption to interdependent civil infrastructure systems. ASCE Journal of Infrastructure Systems, 2015; 10.106

18. Dueñas-Osorio L, Craig JI, Goodno BJ. Seismic response of critical interdependent networks. Earthquake Engineering and Structural Dynamics, 2007; 36:285-306.

19. Wilkinson SM,Dunn S, Ma S. The vulnerability of European air traffic to spatial hazards. Natural hazards, 2012; 60(3), 1027-1036.

20. Prichard OG, Hallett SH, Farewell TS. Soil movement in the UK - Impacts on Critical Infrastructure. ITRC working paper series. http://www.itrc.org.uk/wordpress/wpcontent/PDFs/Soil-movement-impacts-UK-infrastructure.pdf, 2013.

21. Chernick H. Resilient City: the Economic Impact of 9/11. Russell Sage Foundation Publications, 2005.

22. Prager F, Beeler Asay GR, Lee B, von Winterfeldt D. Exploring reductions in London underground passenger journeys following the July 2005 bombings. Risk Analysis, 2011;

\section{$31(5), 773-786$.}

23. Strogatz SH. Exploring complex networks. Nature, 2001; 410 (6825), 268-276.

24. Newman M. Networks: An Introduction. Oxford University Press, 2010.

25. Lewis TG. Network Science: Theory and Applications. John Wiley \& Sons, 2011.

26. Barthelemy M. Spatial Networks. J.physrep, 2011; 499:1-101

This article is protected by copyright. All rights reserved. 
27. Bashan A, Berezin Y, Buldyrev SV, Havlin S. The extreme vulnerability of interdependent spatially embedded networks. Nature Physics, 2013; 9(10), 667-672.

28. Johansson J, Hassel H. An approach for modelling interdependent infrastructures in the context of vulnerability analysis. Reliability Engineering and System Safety, 2010; 95 (12), $1335-1344$.

29. Poljansek K, Bono F, Gutierrez E. GIS-based Method to Assess Seismic Vulnerability of Interconnected Infrastructure: A Case of EU Gas and Electricity Networks. EU JRC 24275, 2010.

30. Zio E, Sansavini G. Modelling interdependent networks systems for identifying cascade-safe operating margins. IEEE transactions on reliability, 2011; 60 (1) 94-101.

31. Hernandez-Fajardo I, Dueñas-Osorio L. Probabilistic study of cascading failures in complex interdependent lifeline systems. Reliability Engineering and System Safety, 2013; 111 (0), $260-272$

32. Ouyang M. Review on modelling and simulation of interdependent critical infrastructure systems. Reliability Engineering and System Safety, 2014; 121, 43-60.

33. Casalicchio E, Galli E. Metrics for Quantifying Interdependencies. Critical Infrastructure Protection II. Chapter 16. Springer, 2008.

34. Zimmerman R, Restrepo CE. The next step: quantifying infrastructure interdependencies to improve security. Int. J. Critical Infrastructures, 2006; 2(2/3) 215-230.

35. Thacker S. Pant R, Hall JW. Characterizing the vulnerability of future configurations of Great Britain's electricity network infrastructure to climate-related hazards. Vulnerability, uncertainty and risk, 2014; pp. 648-657.

This article is protected by copyright. All rights reserved. 
36. Patterson SA, Apostolakis GE. Identification of critical locations across multiple infrastructures for terrorist actions. Reliability Engineering and System Safety, 2007; 92, pp. 1183-203.

37. Jenelius E, Mattsson LG. The vulnerability of road networks under area-covering disruptions. In: proceedings of INFORMS annual meeting, Washington, DC, 2008.

38. Wilson R. Using kernel density estimation to examine changes in voucher density over time. Cityscape: Ajournal of policy development and research, 2012; Volume 14 Number 3.

39. Openshaw S. The Modifiable Areal Unit Problem. London, UK: Geo Books, 1994.

40. Silverman BW. Density Estimation for Statistics and Data Analysis. New York: Chapman and Hall, 1986.

41. Ord JK, Getis A. Local spatial autocorrelation statistics: distributional issues and an application. Geographical Analysis, 1995; 24(3).

42. UK Power Network Services. The Power Behind Airports, 2014.

43. Pant R, Hall JW, Blainey, SP. Vulnerability assessment framework for interdependent critical infrastructures: case-study for Great Britain's railway network. European Journal of Transport and Infrastructure Research, 2016; 16(1), 174-194, ISSN:1567-7141.

44. Civil Aviation Authority (CAA). Civil Aviation Authority: UK Airport Statistics, 2010.

45. Department for Transport (DfT). UK Department for Transport: Maritime and Shipping Statistics, 2012a.

46. Department for Transport (DfT). Road traffic statistics: http://www.dft.gov.uk/trafficcounts/2014.

This article is protected by copyright. All rights reserved. 
47. Department for Transport (DfT). Tag Unit 3.5.6 - Values of Time and Vehicle Operating Costs. London, UK, 2012b.

48. Department of Energy and Climate Change (DECC). Digest of UK Energy Statistics (DUKES), 2012.

49. National Grid. Electricity Ten Year statement, UK Electricity Transmission. National Grid, UK, 2012.

50. Ordnance Survey. OS MasterMap Topography. Ordnance Survey, UK, 2015.

\section{APPENDIX}

Table I: List of assets included in the spatial criticality analysis. Detailing the data sources used to complete the spatial topological network representations and the capacity and demand data used to estimate the functional path set and assign user demands.

\begin{tabular}{|c|c|c|}
\hline & $\begin{array}{c}\text { Spatial and Topological } \\
\text { Asset Attributes }\end{array}$ & $\begin{array}{c}\text { Capacity and Demand } \\
\text { Attributes }\end{array}$ \\
\hline Electricity generation & $\begin{array}{l}\text { Generator node locations } \\
\text { derived using DECC } 2012 \\
\text { DUKES data.(48) }\end{array}$ & $\begin{array}{l}\text { Individual generator capacity } \\
\text { values derived using DECC } \\
2012 \text { DUKES data. }{ }^{(48)}\end{array}$ \\
\hline $\begin{array}{l}\text { Electricity transmission } \\
\text { - Owners: National Grid } \\
\text { - Nodes: } 437\end{array}$ & $\begin{array}{l}\text { Transmission network } \\
\text { derived from National Grid } \\
\text { maps.(49) }\end{array}$ & $\begin{array}{l}\text { User demands derived using } \\
\text { capacity constrained location } \\
\text { allocation - detailed in paper, } \\
\text { based on Thacker et al.(35) }\end{array}$ \\
\hline $\begin{array}{l}\text { Electricity sub-transmission } \\
\text { - Owners: Multiple DNOs }\end{array}$ & $\begin{array}{l}\text { Sub-transmission network } \\
\text { derived from OS MasterMap } \\
\text { topography layer node and }\end{array}$ & $\begin{array}{l}\text { User demands derived using } \\
\text { capacity constrained location } \\
\text { allocation - detailed in paper, }\end{array}$ \\
\hline
\end{tabular}

This article is protected by copyright. All rights reserved. 


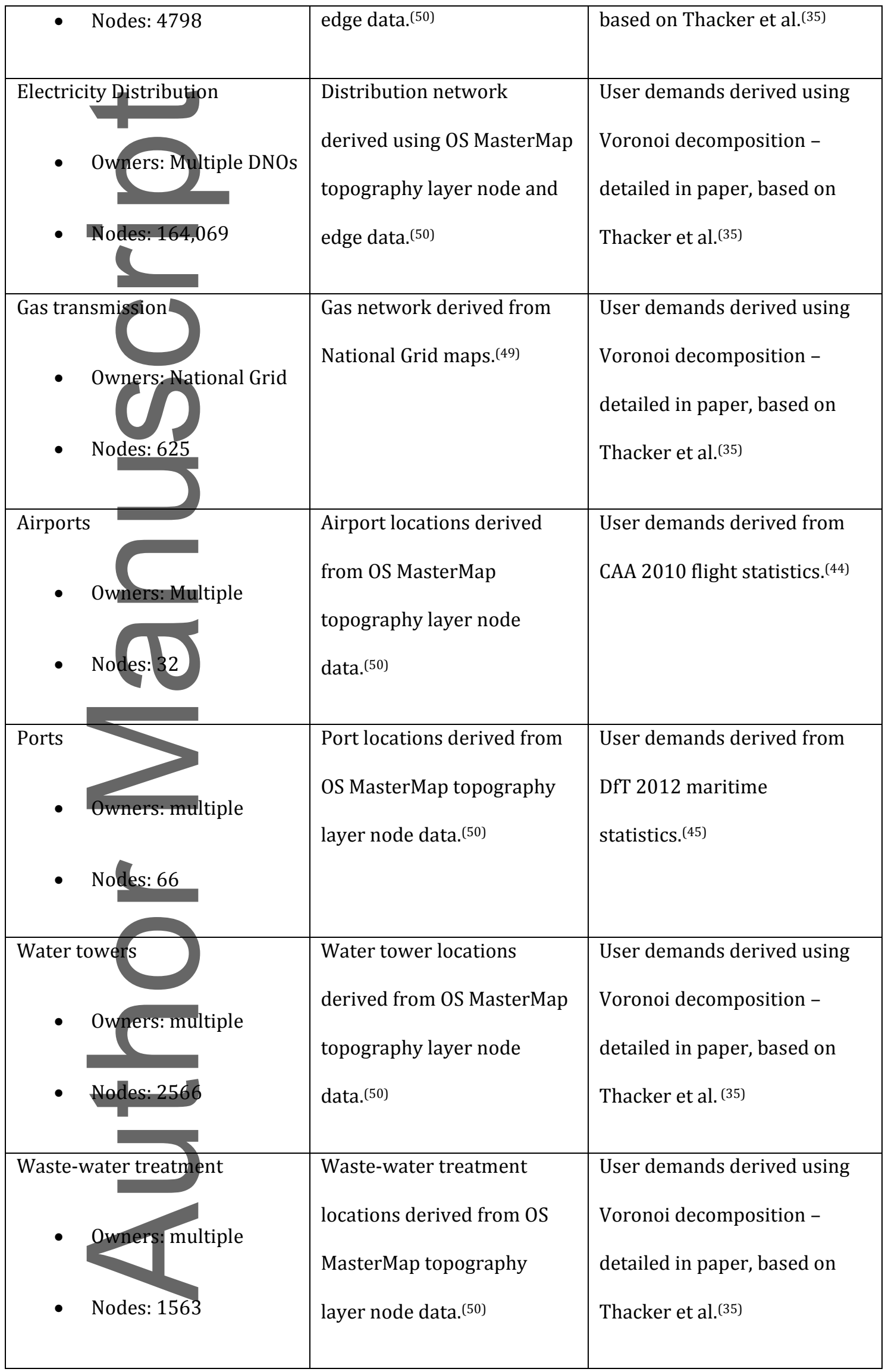

This article is protected by copyright. All rights reserved. 


\begin{tabular}{|c|c|c|}
\hline $\begin{array}{l}\text { - Owners: multiple } \\
\text { - Nodes: } 5226\end{array}$ & $\begin{array}{l}\text { Telecom mast locations } \\
\text { derived from OS MasterMap } \\
\text { topography layer node } \\
\text { data.(50) }\end{array}$ & $\begin{array}{l}\text { User demands derived using } \\
\text { Voronoi decomposition - } \\
\text { detailed in paper, based on } \\
\text { Thacker et al.(35) }\end{array}$ \\
\hline $\begin{array}{r}\text { Railways } \\
\text { - Own } \\
\text { - Node }\end{array}$ & $\begin{array}{l}\text { Railway locations derived } \\
\text { from OS MasterMap } \\
\text { topography layer node } \\
\text { data.(50) }\end{array}$ & $\begin{array}{l}\text { Passenger demands from a } \\
\text { rail trip distribution model, } \\
\text { documented in Pant et al. }{ }^{(43)}\end{array}$ \\
\hline $\begin{array}{r}\text { Roads } \\
\text { - OWr }\end{array}$ & $\begin{array}{l}\text { Road locations derived from } \\
\text { OS MasterMap topography } \\
\text { layer node data.(50) }\end{array}$ & $\begin{array}{l}\text { Passenger demands from DfT } \\
\text { AADF usage statistics, }{ }^{(46)} \text { and } \\
\text { DfT loading factors. }{ }^{(47)}\end{array}$ \\
\hline
\end{tabular}

This article is protected by copyright. All rights reserved. 
a) National infrastructure system $A$

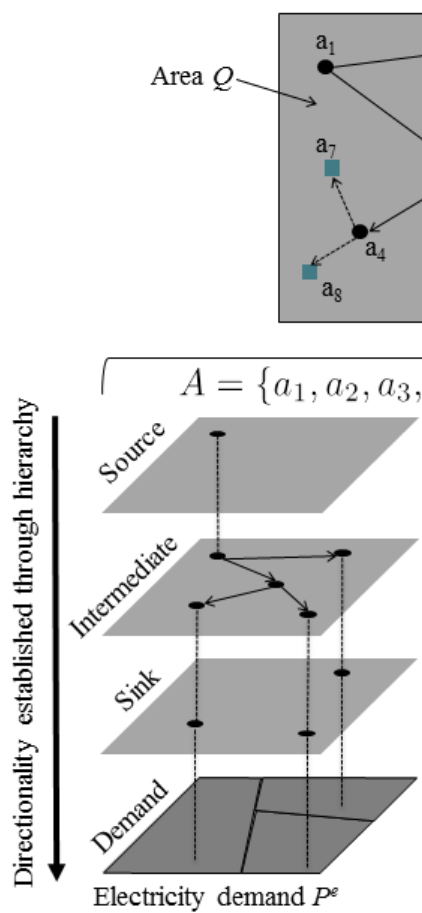

b) Individual asset customer criticality $c_{j}$
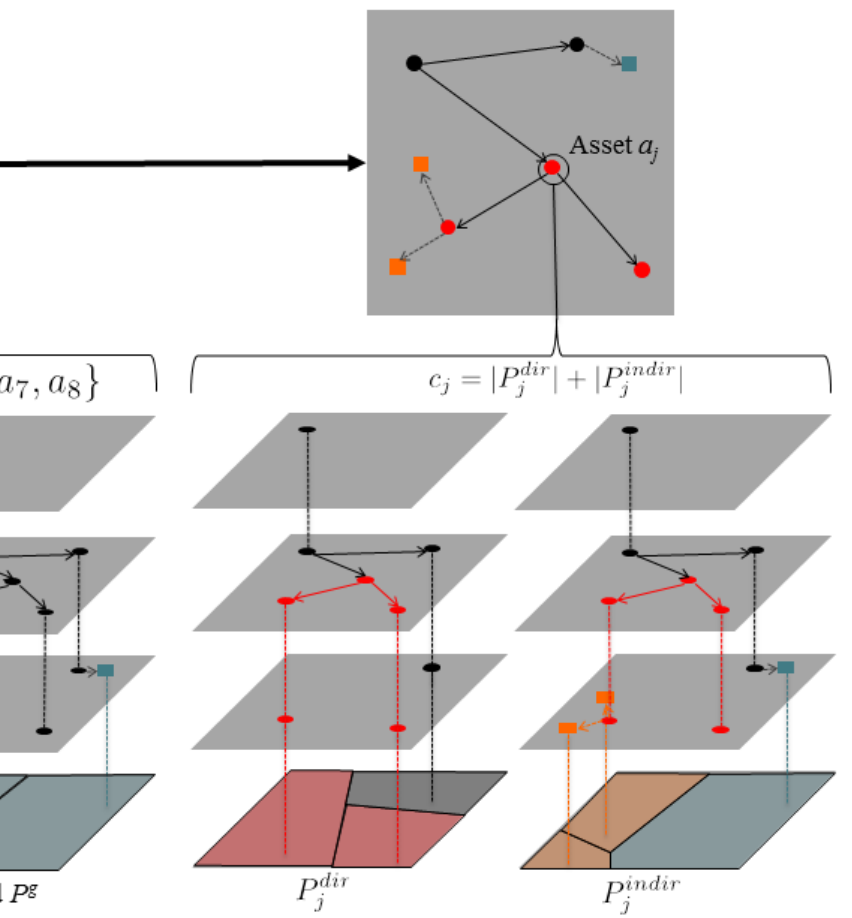

$P_{j}$

Figure 1: The calculation of individual infrastructure asset user criticality values from the mapping of infrastructure network systems and their physical interdependencies and the summation of direct and indirect user demands.

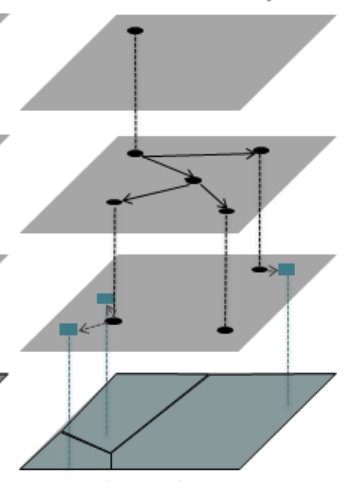

Gas demand $P g$ a) Mapping of key parameters in the Kernel Density Estimation (KDE)

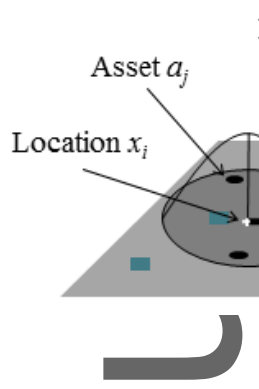

b) Statistical significance testing of $\mathrm{KDE}$ surface to identify geographic hotspots

Figure 2: Highlights the key elements of the Kernel Density Estimation (KDE) generation and hotspots derivation process. Part a). Gives the main parameters used in the KDE to create a continuous criticality surface. Part b). shows how statistical significance testing of the criticality surface is used to identify geographic hotspots of critical infrastructure.

This article is protected by copyright. All rights reserved. 


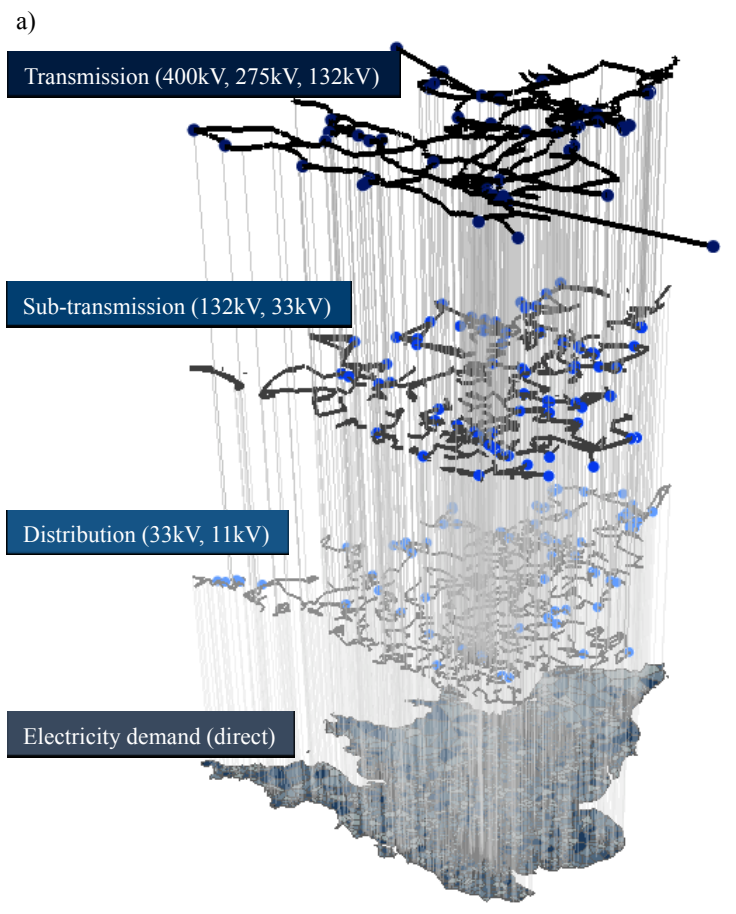

b)
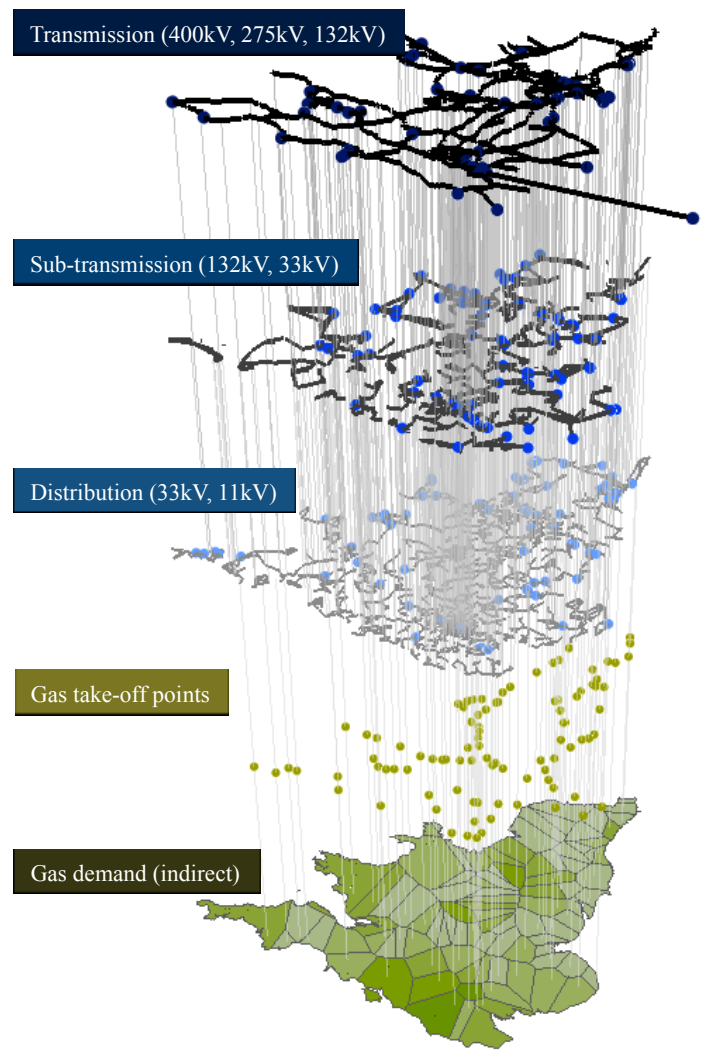

\section{IV}

Figure 3: A representation of the integrated electricity network for England and wales; consisting of the electricity power generation, transmission, sub-transmission, distribution sub-systems. (a) Shows how domestic electricity users at distribution sub-stations place a direct demand. (b) Shows how gas users, connected through a dependency link between the gas and electricity infrastructure place an indirect demand on electricity assets.

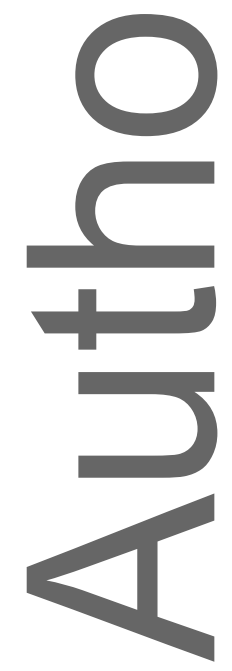

This article is protected by copyright. All rights reserved. 

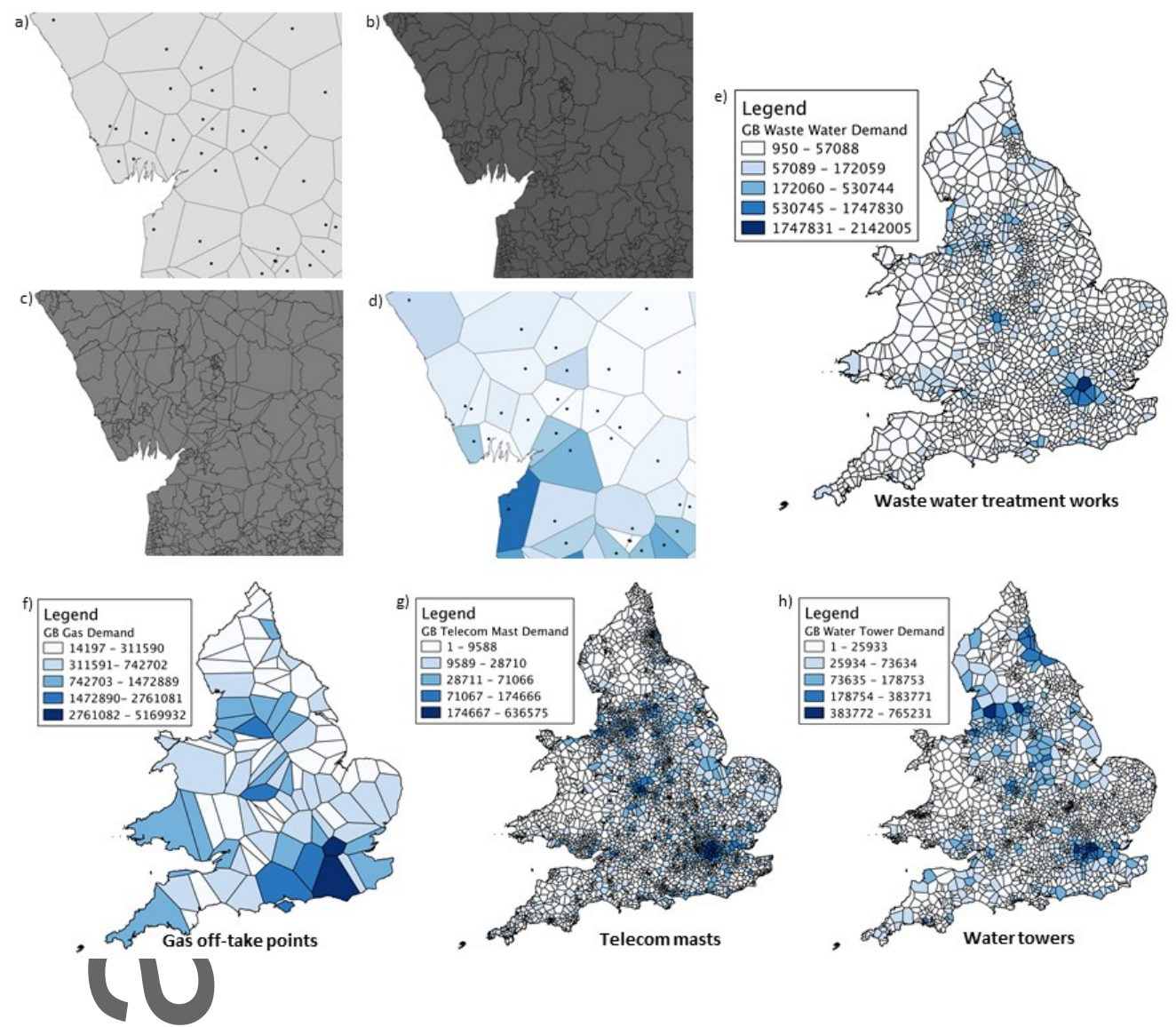

Figure 4: Stages in assigning users to assets; (a) introduces a set of asset footprints. (b) Provides a view onto ward level population data. (c) Represents the union of both the asset footprint and the bounded population data. (d) Gives user estimates transferred to asset footprints (e), (f), (g) and (h) provide user assignments, with user magnitude highlighted on a colour scale derived for waste water treatment works, gas off-take points, telecom masts and water towers respectively.

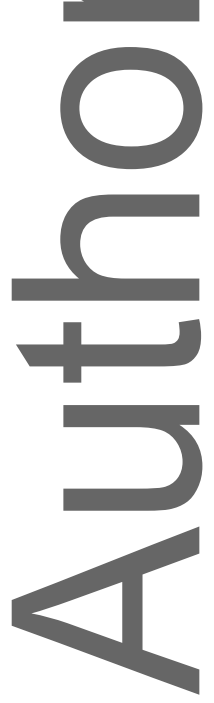

This article is protected by copyright. All rights reserved. 


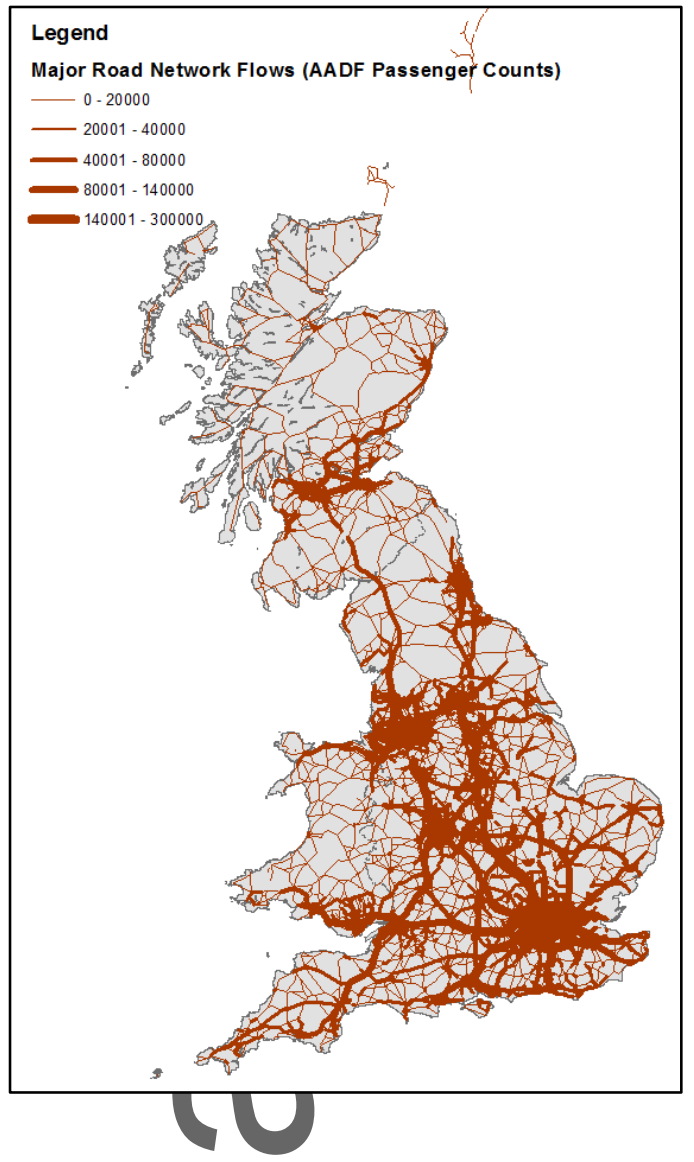

(a)

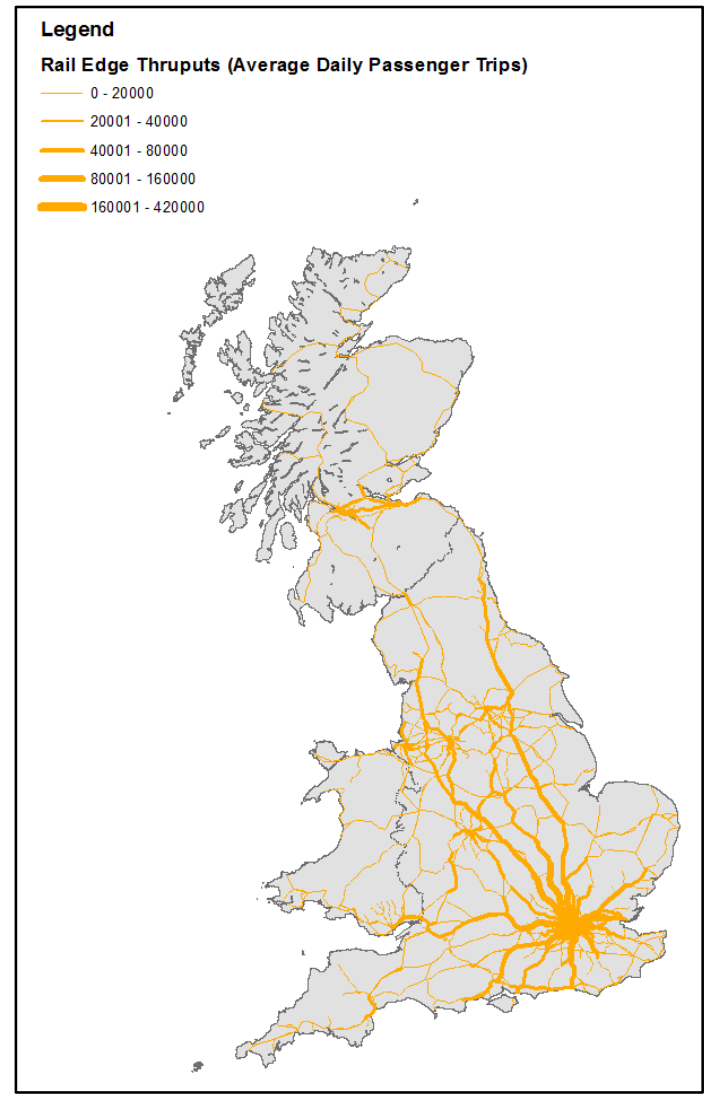

(b)

Figure 5: (a) Hllustration of the average annual daily flows (passenger numbers) along links on the major road network from Great Britain. (b) Edge Criticality: which represent the passenger throughputs at each railway network edge (track section).

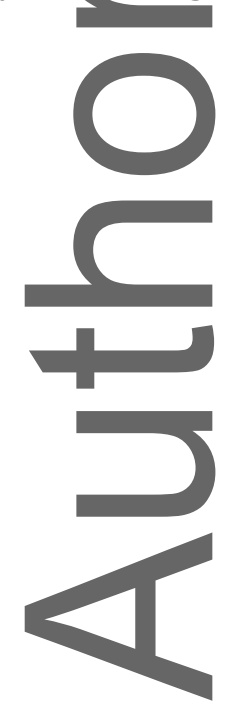

This article is protected by copyright. All rights reserved. 


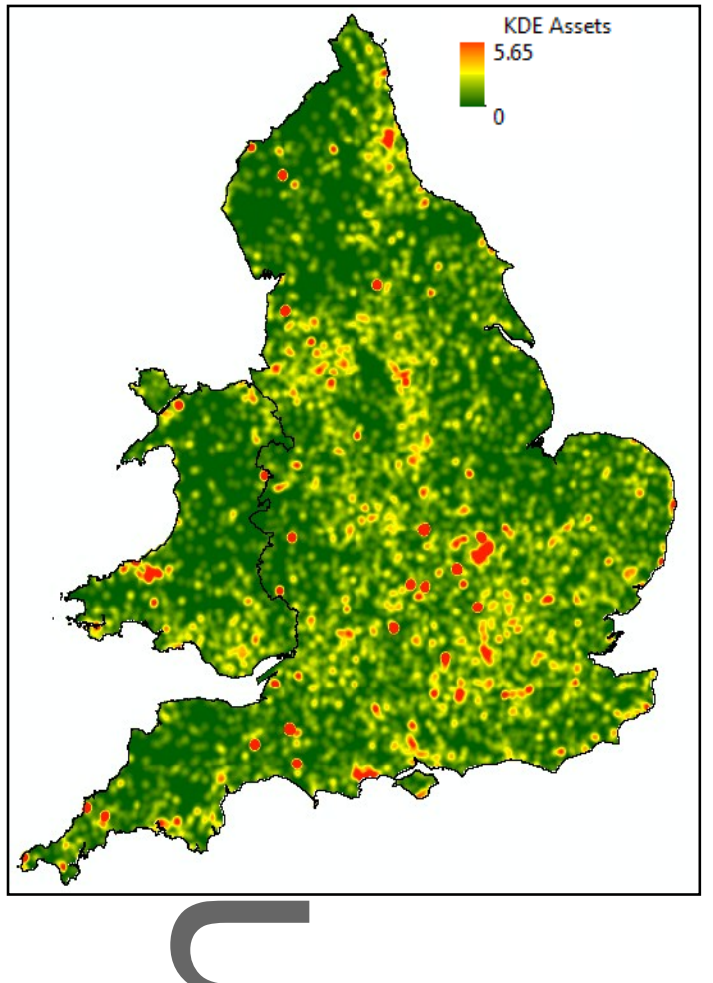

(a)

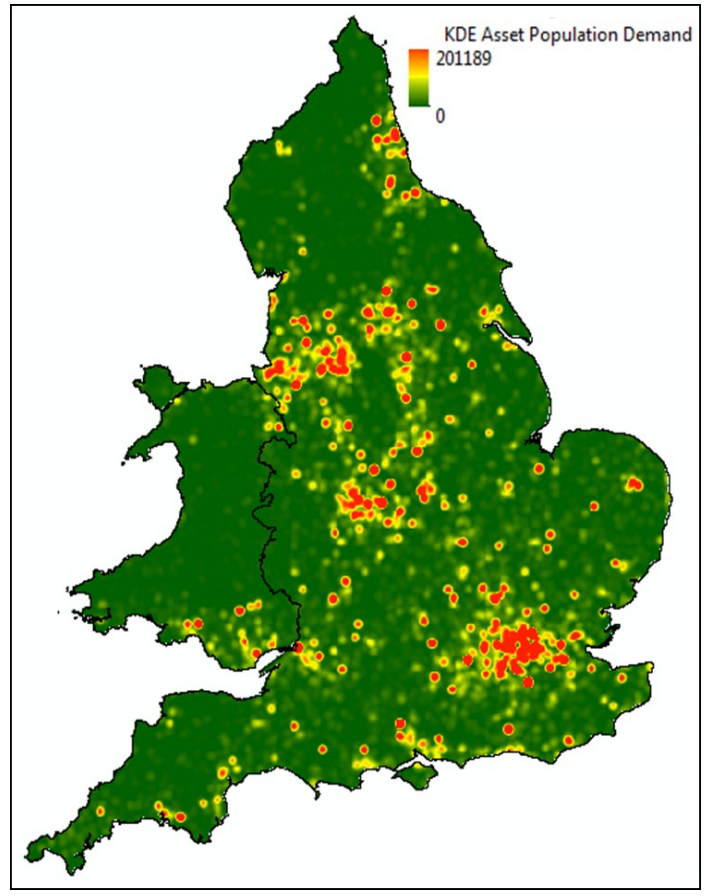

(b)

Figure 6: (a) Kerneldensity estimated infrastructure asset spatial density (GSP, gas, telecoms, water and water treatment assets). (b) Kernel density estimated infrastructure asset user demand (GSP, gas, telecoms, water and water treatment assets).

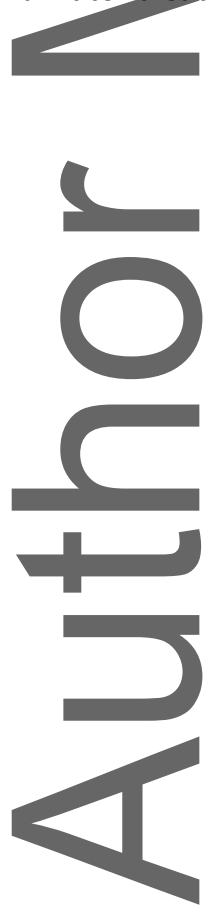

This article is protected by copyright. All rights reserved. 


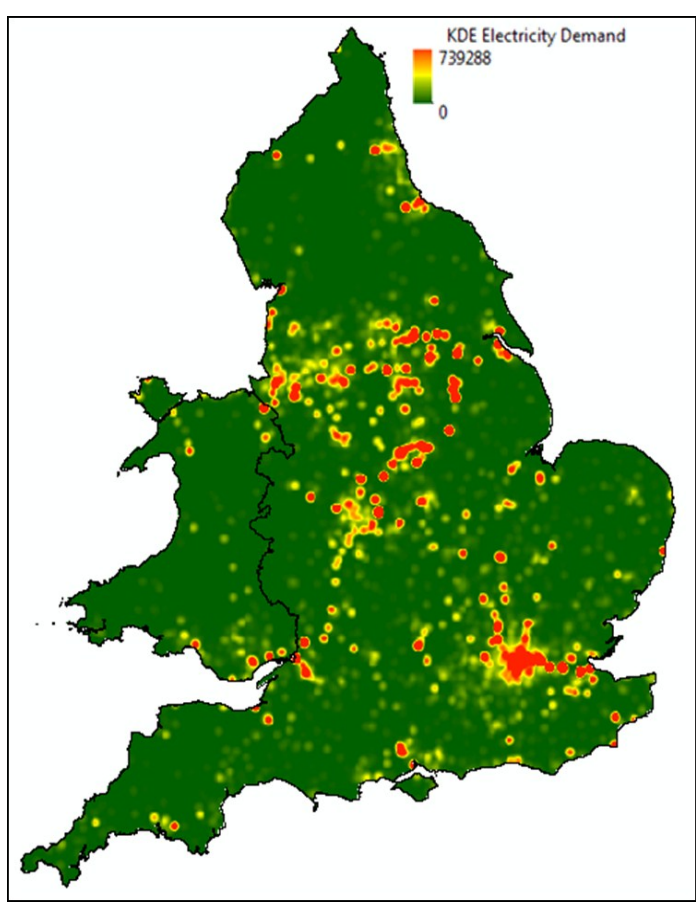

(a)

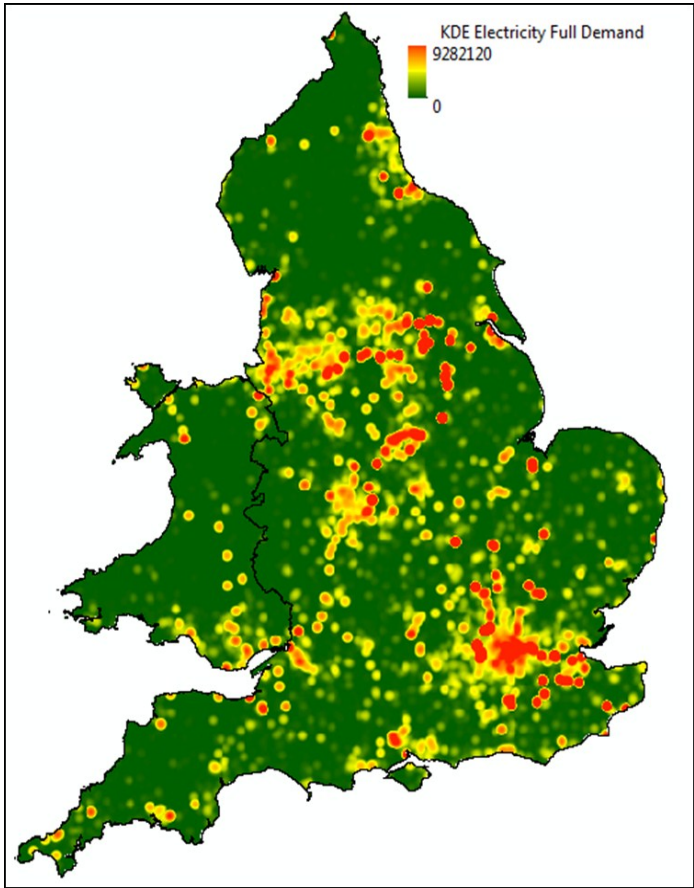

(b)

Figure 7: (a) Kernel density estimated electricity user demand (no dependent demand). (b) Kernel density estimated full electricity user demand (direct and indirect user demands - user criticality) including GSP, gas, telecoms, water and water treatment assets dependency.

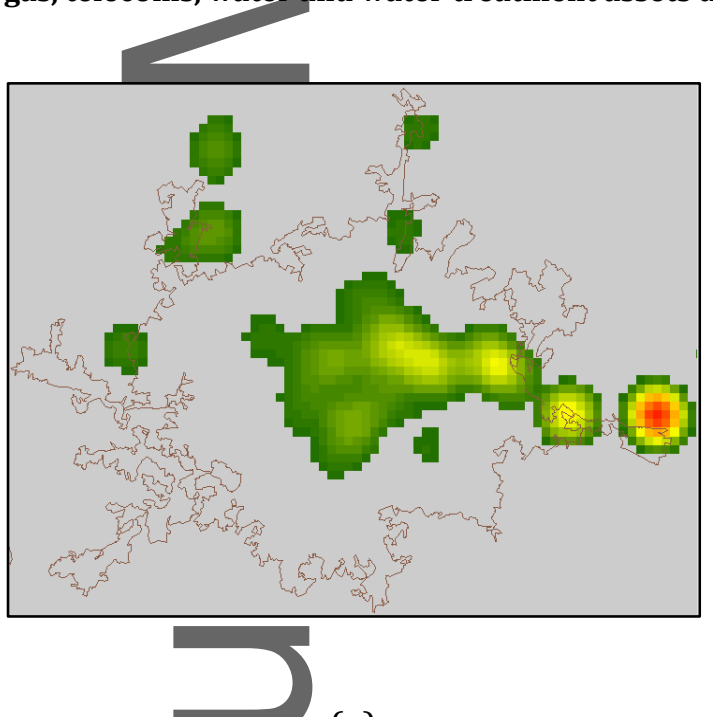

(a)

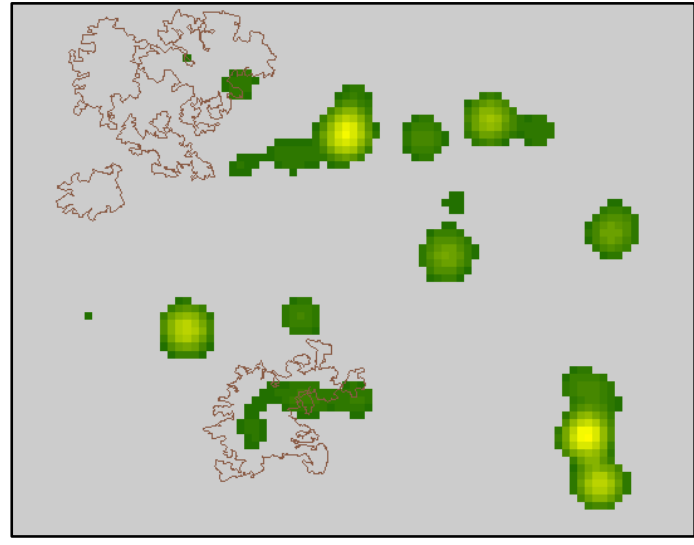

(b)

Figure 8: (a) London's electricity infrastructure asset user demand hotspots at a $99 \%$ significance level (Zscore $>2.56$ ). (b) Electricity infrastructure asset user demand hotspots at a $99 \%$ significance level (Z-score $>$ 2. 56) for South Yorkshire.

This article is protected by copyright. All rights reserved. 


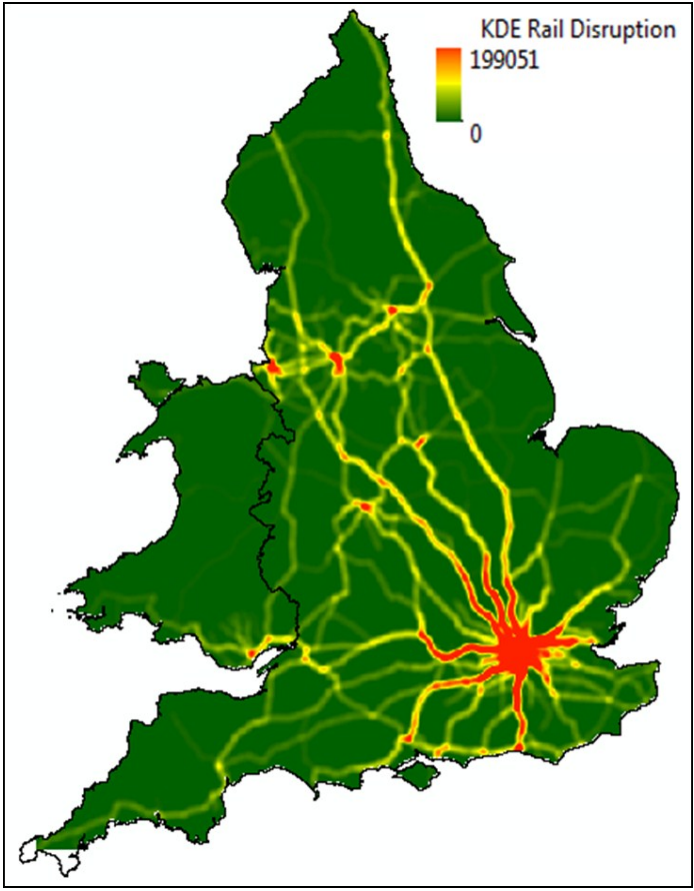

(a)

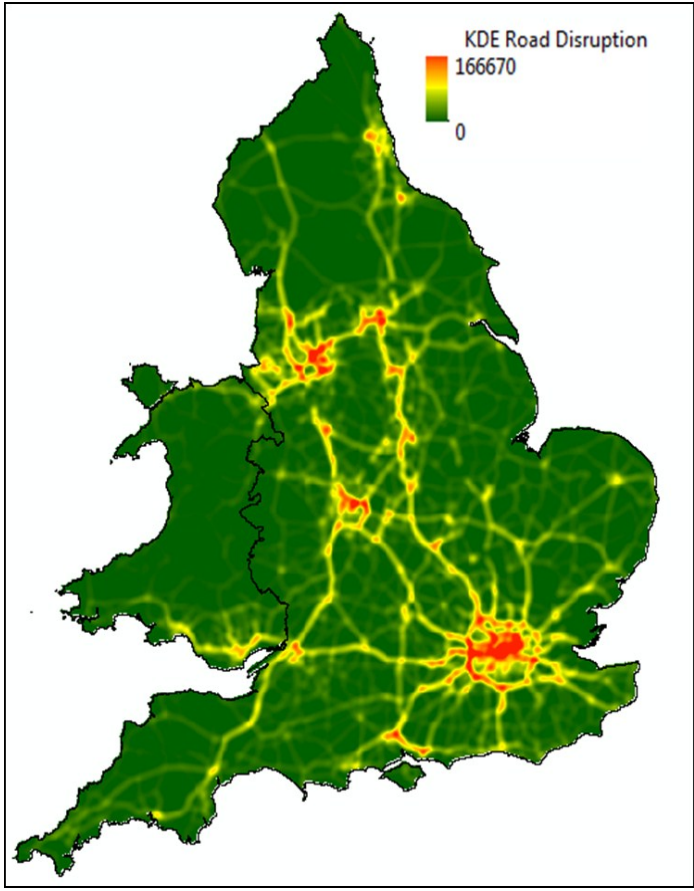

(b)

Figure 9: (a) Kernel density estimated rail disruption (stations and track). (b) Kernel density estimated road network disruption on the basis of passengers.
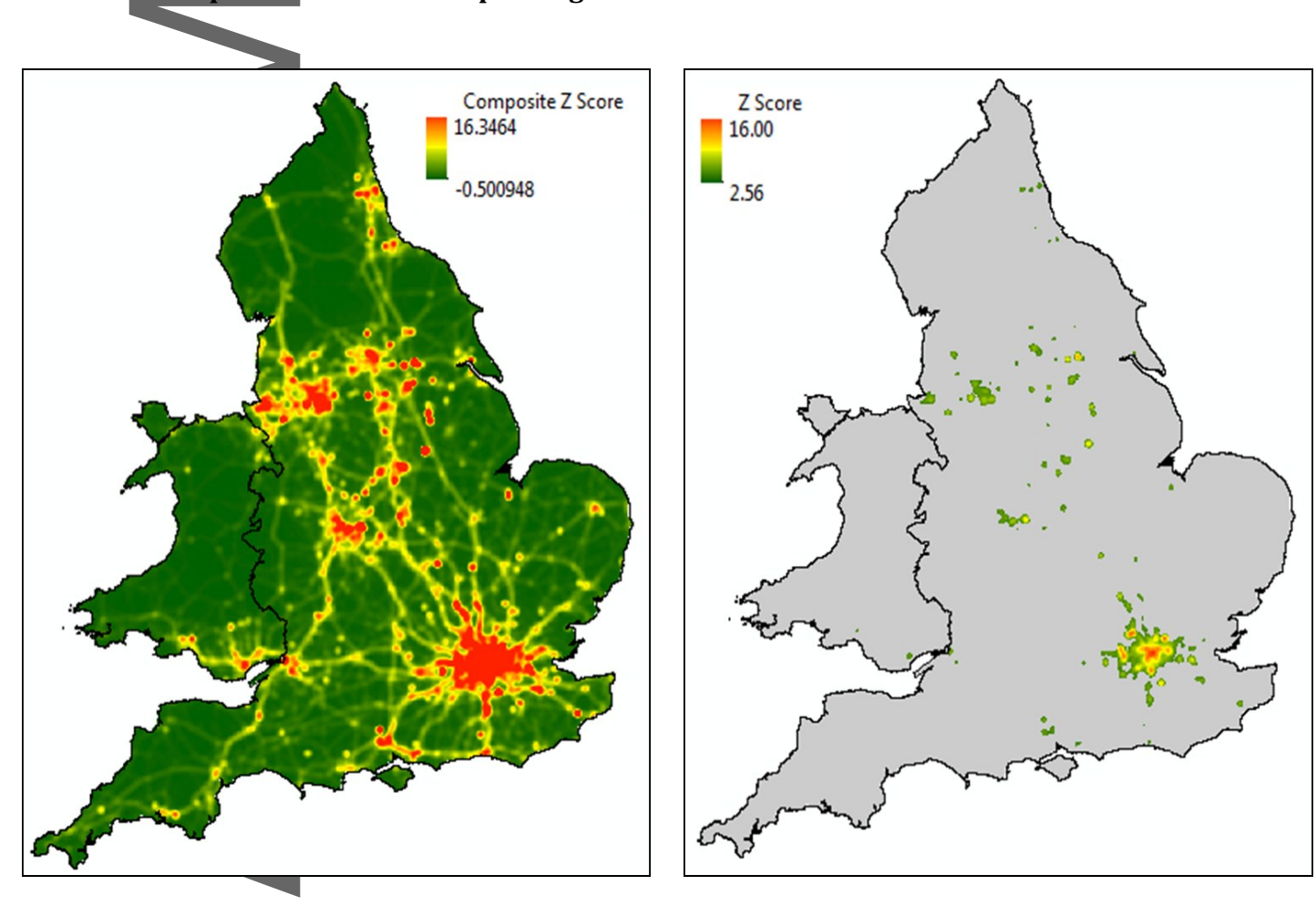

This article is protected by copyright. All rights reserved. 

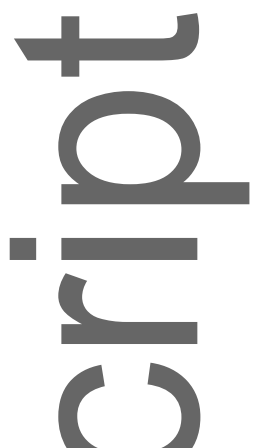

Figure 10: (a) Composite $Z$ scores of user demand and disruption of assets, electric network, rail and road (b) Statistically significant composite hotspots at a 99\% significance level (Z-score > 2.56).

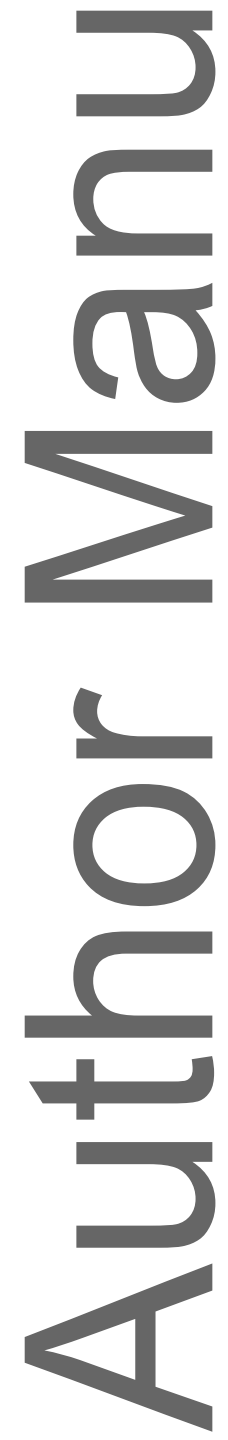

This article is protected by copyright. All rights reserved. 


\section{University Library}

\section{- M M N E R VA A gateway to Melbourne's research publications}

Minerva Access is the Institutional Repository of The University of Melbourne

Author/s:

Thacker, S;Barr, S;Pant, R;Hall, JW;Alderson, D

Title:

Geographic Hotspots of Critical National Infrastructure

Date:

2017-12-01

Citation:

Thacker, S., Barr, S., Pant, R., Hall, J. W. \& Alderson, D. (2017). Geographic Hotspots of Critical National Infrastructure. RISK ANALYSIS, 37 (12), pp.2490-2505. https:// doi.org/10.1111/risa.12840.

Persistent Link:

http://hdl.handle.net/11343/293016 